\title{
Biotechnology for the Environment
}

\section{DOE Grant \# DE-FG03-00ER63027}

\author{
A Final Report for the \\ Joint United States - European Union
}

Support for Short-term Exchanges of Early Career Scientists

\author{
Submitted by: \\ Joseph M. Suflita' and Judy D. Wall ${ }^{2}$ \\ ${ }^{1}$ Department of Botany \& Microbiology, University of Oklahoma \\ ${ }^{2}$ Biochemistry Department, University of Missouri-Columbia
}




\section{DISCLAIMER}

This report was prepared as an account of work sponsored by an agency of the United States Government. Neither the United States Government nor any agency Thereof, nor any of their employees, makes any warranty, express or implied, or assumes any legal liability or responsibility for the accuracy, completeness, or usefulness of any information, apparatus, product, or process disclosed, or represents that its use would not infringe privately owned rights. Reference herein to any specific commercial product, process, or service by trade name, trademark, manufacturer, or otherwise does not necessarily constitute or imply its endorsement, recommendation, or favoring by the United States Government or any agency thereof. The views and opinions of authors expressed herein do not necessarily state or reflect those of the United States Government or any agency thereof. 


\section{DISCLAIMER}

Portions of this document may be illegible in electronic image products. Images are produced from the best available original document. 
Project Summary: The EU-US Task Force on Environmental Biotechnology obtained support for short-term transatlantic exchanges of early career scientists designed to foster collaborative interactions and to enhance the professional development of the exchange fellows through the acquisition of expertise in microbial biotechnology. Not all of the available funds were expended. Travel worldwide is only now approaching preSeptember 11, 2001 levels. Funds received from the ONR were exhausted during this round of exchanges while NSF granted a no-cost extension for one year. The DOE refused a no-cost extension request and steps are underway to return the unexpended funds. Five participants received funds for exchange research visits in EU laboratories, in addition to the eleven fellows funded during the first round of exchanges. This progtam continues to meet the mission of fostering the collaborative exchange of scientific talent between the United States and the European Union.

Background of Project: The United States and the European Union seek costeffective strategies to reduce the human and environmental risks that attend sites contaminated with hazardous materials. The acknowledgment that environmental issues know no national boundaries, and the recognition that the US and the EU share considerable expertise in the use of the modern tools of molecular biology, led to a unique transatlantic cooperative initiative to develop biotechnology for the remediation of contaminated environments. The cooperative efforts were initiated through the formation of the EU-US Biotechnology Task Force composed of a dozen established scientists and administrators from the EU and an equal number from the US. In 1994, these individuals met in Brussels, Belgium, to discuss issues and methods of cooperation in the growing 
field of environmental biotechnology. From the Task Force, a smaller Working Group on Biotechnology for the Environment (Appendix 1) was formed that has been cochaired by Dr. Anna Palmisano from the US and Dr. Ioannis Economidis from the EU. The underlying premise of the efforts of the Working Group was that meaningful and long-lasting collaborations develop only when researchers share mutual respect and trust developed through working together. In addition, it was agreed that an investment in early career scientists would provide a greater benefit for the development of the field. This logic ultimately culminated in the development of a project to initiate short-term collaborative exchanges between US and EU investigators.

Funding Report: In 2000, having identified important research areas and being fully aware of the added benefits of transatlantic cooperation, the Working Group sought to foster collaboration through the direct exchange of scholars between laboratories. In 2001 , initial grant support was obtained from three federal agencies for short-term transatlantic exchange fellowships that targeted early career scientists. Since at the end of the initial project period the interest within the scientific community in the opportunity offered was high, the same agencies invested additional monies for the same purpose (Table 1 \& 3). However, travel of all sorts was negatively impacted by a series of world events.

Table 1. Support obtained for EC-US Biotechnology Exchange Fellowships

\begin{tabular}{|c|c|c|}
\hline Agency & Grant No. & Amount \\
\hline US DOE & DE-FG03- & $\$ 35,223$ \\
& 00ER63027/A002 & \\
\hline
\end{tabular}




\begin{tabular}{|c|c|c|}
\hline NSF & DEB-0302760 & $\$ 26,091$ \\
\hline DOD-ONR & N00014-01-1-0316 & $\$ 13,915$ \\
\hline
\end{tabular}

In the latest round of funding, a total of $\$ 75,229$ was obtained (Table 3) and efforts were made to extend the monies as far as possible. The universities involved waived all indirect cost recovery for the project. Conference calls and email were used for decision making by the Task Force members. However, funds were expended to advertise the program vigorously on several occasions. Ultimately, five young scientists were supported for study in three EU countries including, Denmark, Sweden and Germany (Table 2). Clearly this was fewer than the number supported in the previous round of fellowships and fewer than anticipated when the grant proposals were crafted and originally submitted. We believe the reasons for the decreased number of participants are complex. However, it is clear that the post-9/11 world has been permanently and irretrievably altered by world events and the perceptions of young scientists are seemingly no exception. The impact of international uncertainty on foreign travel can be easily measured. Terrorism, major world conflagrations such as events in Afghanistan and the Iraqi war, as well as several health scares like SARS, exacerbated the decline in travel post-9/11. A slow and uneasy return to foreign travel is only now beginning to be realized and complete recovery is not expected until 2007.

Table 2. EU-US Biotechnology Exchange Fellowship Awardees 2003-2004.

Dollar

Fellow Amount U.S. Mentor
E.U. Host

Location
Duration

(Mos.) 


\begin{tabular}{|c|c|c|c|c|}
\hline Lisa Strong & 7,702 & Larry Wackett & Janet Jansson & Uppsala \\
\hline Sabrina Mueller & 2,543 & Brian Kinkle & Soren Sorensen & Copenhagen \\
\hline Kelli Palmer & 3,911 & $\begin{array}{l}\text { Marvin } \\
\text { Whiteley }\end{array}$ & Soeren Molin & Copenhagen \\
\hline Kelly Bender & 5,700 & Judy Wall & Gerhart Wagner & Uppsala \\
\hline Lanie Petrie & 5,750 & Joel Kostka & Harold Drake & Germany \\
\hline
\end{tabular}

The exchanges fostered the acquisition of new skills and expertise in environmental technology during a one- to six-month stay in the host laboratory. The host institution provided the opportunity for a new skill to be leamed or improved, laboratory infrastructure, basic supplies and exposure to an appropriate intellectual climate (e.g. access to faculty/staff, lectures, seminars, etc). The funding was used to support travel to the host laboratory as well as housing and living supplement. Salary for the exchange fellow was NOT covered by the funds.

Table 3 indicates how the funding from the three granting agencies was utilized to support the fellowship exchange program. All monies received from ONR were expended within the grant period. Fellowship support and advertising accounted for $44.3 \%$ and $21.2 \%$ of the DOE and NSF funding, respectively. While a no-cost extension was received from the NSF till Feb., 2006, DOE has decided otherwise and is recouping the residual funds.

Table 3. Specific utilization of the grant funds. 


\begin{tabular}{|l|r|r|r|r|}
\hline & \multicolumn{1}{|l|}{ DOE* $^{*}$} & \multicolumn{1}{l|}{ NSF*** } & \multicolumn{1}{l|}{ ONR } & \multicolumn{1}{l|}{ Totals } \\
\hline Award Amount & $35,223.00$ & $26,091.00$ & $13,915.00$ & $75,229.00$ \\
\hline Fellowships & $11,613.00$ & $3,283.00$ & $10,710.00$ & $25,606.00$ \\
\hline Advertising & $3,989.34$ & $2,258.10$ & $3,205.00$ & $9,452.44$ \\
\hline Balance & $19,620.66$ & $20,549.90$ & -0 & $40,170.56$ \\
\hline & & & & \\
\hline *Returned & $19,620.66$ & & & $19,620.66$ \\
\hline **Extension 2/28/06 & & $20,549.90$ & & $20,549.90$ \\
\hline
\end{tabular}

Benefits: The short-term exchanges of early career scientists had at least three major benefits. Most obviously, benefits will accrue to the exchange fellow. Extending the range of experimental skills for addressing environmental problems will substantially augment the training of the fellows in the discipline. The exchange fellows have had the opportunity to develop their careers in important ways. Clearly, they were able to supplement their networking skills in a manner not usually accorded the younger investigator. Moreover, the exchange fellows enjoyed a broader perspective in their appreciation for the global aspects of environmental issues.

Secondly, the exchanging laboratories also benefited from this program. The laboratories acting as hosts acquired new skills, techniques, and perspectives from the visiting scholar. Clearly the home institution was enriched in a similar manner upon the return of the fellow. The funding allowed laboratories with collaborative interests to bolster their interaction through the exchange of personnel and to open communication lines that lead to functional cooperation. The program had a profound impact on the ability of the US and EU to develop affordable remediation strategies by sharing intellectual capital in environmental biotechnology. Collaborating scientists working together on common environmental concems fostered cooperation in important areas of research. Thirdly, the exchanges had a myriad of societal implications. The pooling 
of scientific expertise from both sides of the Atlantic helped to accelerate the pace of technology designed to provide effective and environmentally sound solutions to environmental contamination problems. Such technology will in turn reduce the human and environmental risks associated with hazardous materials.

In addition, international research and development policies include objectives to foster competitiveness in the global market place. The exchange program undoubtedly assisted with this objective through the sharing of information in environmental remediation - an important economic growth area for both the US and the EU.

Besides the anticipated scientific and economic advances, the proposed exchange program had additional tangible benefits associated with increased exposure of young scholars to cultural differences. The type of cooperation in research exemplified by the exchanges plays an important role in the process of societal and cultural understanding and as a tool for the development of productive external relations amongst participants. Such aspects belped ensure that the total benefits of the program far exceed the sum of the component parts.

Method of Recruitment: Applicants were recruited on a national basis from microbial ecology, molecular microbiology, and environmental science laboratories through advertisements in Science, Environmental Science and Technology and ASM News. Announcements were also posted on appropriate professional websites and an interactive internet web site was established to facilitate online application procedures (http://www.biochem.missouri.edu/EC-US-BiotechFellow). Applications from people with diverse racial, ethnic, and cultural backgrounds were encouraged. 
The Selection Process: A US selection committee composed of four members of the Working Group (including one EU member) and two industrial representatives directly involved in environmental remediation activities reviewed the applications received electronically and then responded electronically with their vote. Since this process was all electronic, a rolling approval of applications was possible. Applications were considered continuously.

Selection Criteria: Participants must have been US citizens or permanent residents at the time of their application. Additionally, they must have been at least in their third year of predoctoral studies or awarded the $\mathrm{Ph} . \mathrm{D}$. no more than four years from the application deadline. The applicant must have been training in the field of microbiology with a demonstrable interest in environmental aspects as a professional goal. The candidate's application was supported by transcripts of graduate training, a one-page description of the research/training plan for the transatlantic exchange, a letter of support from the Ph.D. or postdoctoral advisor and from the exchange host institution or scientific mentor. It was incumbent on the applicant to justify how the exchange would serve to augment their educational goals, facilitate their scientific research in the discipline, and lead to collaborative exchange with another laboratory. 
Appendix 1: The EU-US Biotechnology Working Group

European members of the Working Group are:

Spiros Agathos - Univ. Catholique de Louvain, BE

Victor de Lorenzo - UAM, ES

Ioannis Economidis- European Commission

Juan Ramos- CSIC, ES

The US participants include:

Michael Brammuci - Dupont Chemical Co.

Jerry Kukor - Rutgers Univ.

Joseph Suflita - Univ. of Oklahoma

Judy Wall - Univ. of Missouri

Lily Young - Rutgers Univ.

Gerben Zylstra - Rutgers Univ 